\title{
THE TEACHING OF ASTRONOMY AT UNIVERSITY LEVEL IN PORTUGAL
}

\author{
M.T.V.T. Lago \\ Grupo de Matemática Aplicada, University of Porto, Portugal
}

\section{Introduction}

In 1984, the University of Porto started a program for the first degree in astronomy in a Portuguese university. Jointly offered by the Physics and Applied Mathematics Departments at the School of Sciences, the degree is strongly marked by the interdisciplinary character essential for the teaching of modern astronomy. It includes 37 per cent in physics, 32 per cent in mathematics, 25 per cent in astronomy, and 6 per cent in chemistry, geology, mathematics, or physics. Its structure in course units comprises:

\begin{tabular}{lll}
\hline \multirow{3}{*}{ 1st year } & 45 to $50 \%$ & Mathematics \\
& 28 to $30 \%$ & Physics \\
& 11 to $12 \%$ & Applied Mathematics \\
& 11 to $12 \%$ & Astronomy \\
\hline \multirow{3}{*}{ 2nd year } & 49 to $50 \%$ & Physics \\
& 24 to $26 \%$ & Mathematics \\
& $26 \%$ & Applied Mathematics \\
\hline \multirow{3}{*}{ 3rd year } & $63 \%$ & Physics \\
& $25 \%$ & Astronomy \\
& $12 \%$ & Applied Mathematics \\
\hline & $75 \%$ & Astronomy \\
4th year & $25 \%$ & Physics, Applied Mathematics, \\
& & Chemistry, or Geology. \\
\hline
\end{tabular}

Most of the initial three years provides basic training in mathematics and physics, except for an introductory course (first year) intended as an overview of modern astronomy and aiming at keeping alive the student's enthusiasm. In the 3rd year, Astronomy I and II appear as basic courses. Finally, the 4th year includes 6 courses in various astronomical topics, such as Formation and Evolution of Stars, Stellar Structure, Cosmology, Astrometry, Extragalactic Astronomy, etc. The list of these topics changes every year and is naturally strongly dependent on the availability of lecturers (local and invited). The inclusion in some of these courses of units of 10 to 15 hours delivered by visiting professors or researchers has proven very stimulating. These units have the great advantage of exposing the students to different people and styles of presentation and help to compensate for the lack of "people 
around," considering that the number of astronomers in Portugal is presently so small. We are at least one order of magnitude below the European average of 1 to 2 astronomers per 100,000 inhabitants.

\section{The European Astrophysical Doctoral Network}

Further to the astronomy degree, complementary education is also starting to be provided through the European Astrophysics Summer Schools organized by the European Astrophysical Doctoral Network. This consortium of 14 European countries represented by one or two universities from each nation is aimed at:

- the exchange of doctoral students, on a short time scale or for a full thesis work;

- post-doctoral interchange and collaboration; and

- through the organization of regular European Astrophysics Summer Schools to offer the European students beginning doctorates in astrophysics a common level in the most fundamental fields as well as an opportunity to meet with colleagues and experts in those fields. It has both national and European community support.

\section{The Center for Astrophysics at the University of Porto}

Yet another component relevant for the teaching of astronomy at the University of Porto has to do with recent developments in the University itself. As a result of both National Research Council and University support, a Center for Astrophysics has been funded and is starting its activities at the University of Porto. Although its main objective is to provide infrastructure and support for research, it also specifically includes a component relating to the teaching of astronomy, both at

i) University level - providing the conditions for the visitors at the Center to collaborate in teaching through the previously mentioned short course units or longer ones; involving the terminal-year students in the Center's research projects;

ii) lower education level - from primary schools to higher education; there is a set of well-defined projects based on the interaction between the Center, the astronomy students, and the schools; however, the space allocated to this paper does not allow further details.

Of no less importance is the scheme for grants associated with the Center for Astrophysics. The first nationwide competition has awarded to selected candidates grants for a Ph.D. in astronomy at well known institutions, on the condition of their future association with the Center, where they must return once they have finished the doctorate. This condition, we hope, will allow us to gain the critical mass so necessary not only for research but also for good quality education as well. 
The University of Porto's Center for Astrophysics is also involved in other very interesting and important actions in education in astronomy. However, they are still in a negotiation stage.

\section{Conclusions}

For those of you who read the report " 1987 - The Year of Astronomy in Portugal?" published in the January issue of the IAU Commission 46 Newsletter, I would like to conclude that 1988 seems to be as important for astronomy in Portugal as 1987. Most of our proposals have been approved and already partially financed; others seem well on their way. And I will finish with the same sentence as in that report:

"Years of low profile and little activity will take time and effort to be replaced. Mentalities probably will take even longer to change. But the times are of optimism and strong hopes in a brighter future."

\section{Acknowledgments}

The partial support of travel grants from the IAU and of JNICT through Projecto $87 / 27$ is gratefully acknowledged.

\section{ASTRONOMY EDUCATION IN HUNGARY}

Gábor Szécsényi-Nagy

ELTE Csillagászati Tanszék, Department of Astronomy, Eötvös University, H-1083 Budapest, Kun Béla tér 2, Hungary

\section{Introduction: The Hungarian Educational System}

Our educational system, like that of any other country, has grown up to meet the needs of the environment in which it developed. Perhaps its most distinctive feature is its emphasis on education of the masses rather than on education of the intellectuals.

The philosophy of the Hungarian educational system is that a democracy depends upon a well-informed electorate, and that therefore each citizen should receive the best education possible. As a result, in our country most children in the same community attend school together from kindergarten through secondary school practically regardless of differences in intellectual ability or in family background. 